Çukurova Üniversitesi Mühendislik Mimarlık Fakültesi Dergisi, 34(2), ss. 267-277, Haziran 2019

Çukurova University Journal of the Faculty of Engineering and Architecture, 34(2), pp. 267-277, June 2019

\title{
Katı Nem Alıcı Bir Rotorun Farklı Çalışma Şartları için Modellenmesi Kamil Neyfel ÇERÇi ${ }^{1}$, Ertaç HÜRDOĞAN ${ }^{* 1}$, Osman KARA ${ }^{1}$ \\ ${ }^{1}$ Osmaniye Korkut Ata Üniversitesi, Mühendislik Fakültesi, Enerji Sistemleri Mühendisliği Bölümü, Osmaniye
}

\section{Öz}

Geliş tarihi: 18.04.2019 Kabul tarihi: 28.06.2019

\begin{abstract}
İklimlendirme sistemleri, yaz ve kış şartlarında mahaller içerisinde istenilen konfor şartlarının elde edilebilmesi için havanın nemini, sıcaklığını ve hava kalitesini kontrol edebilen sistemlerdir. İklimlendirme sistemlerinde ve son zamanlarda kurutma sistemlerinde, havanın neminin alınabilmesi için katı nem alıcı rotorun kullanımı gün geçtikçe yaygınlaşmaktadır. Bu sebeple çoğu araşırmacı nem alıcı rotorların tasarımı, modellenmesi ve optimizasyonu üzerine farklı çalışmalar gerçekleştirmişlerdir. Katı nem alııı rotorda, ısı ve kütle transferi birlikte gerçekleştiğinden prosesi matematiksel olarak modellemek çok zor bir işlemdir. Bu zorluğun giderilmesi üzerine Jurinak [8] basit bir model geliştirmiş ve bu model çoğu araştırmacı tarafindan kullanılmaktadır. Fakat bu model sınırlı çalışma koşulları (özellikle yüksek hava debisi) için kullanılabilecek bir yapıya sahiptir. Bu çalışmada, Jurinak'ın modeli baz alınarak, düşük hava ihtiyacının olduğu uygulamalarda, farklı çalışma şartları altında kullanılabilecek katı nem alıcı bir rotor için bir model geliştirilmiş ve elde edilen sonuçlar ile üretici verileri kıyaslanarak modelin kullanılabilirliği test edilmiştir. Çalışma sonunda, geliştirilen model ile elde edilen sonuçların, üretici verileri ile iyi bir uyum içinde olduğu ve modelin farklı çalışma şartları için kullanımının uygun olduğu görülmüştür.
\end{abstract}

Anahtar Kelimeler: Nem alma, Katı nem alıcı, Rotor, Modelleme

Modeling of a Solid Desiccant Wheel for Different Operating Conditions

\begin{abstract}
Air conditioning systems are the systems that can control humidity, temperature and air quality of the air in order to obtain the desired comfort conditions under summer and winter conditions. The usage of solid desiccant wheel to remove the moisture from the air is becoming more common in air conditioning systems and recently in drying systems. For this reason, most researchers have carried out different studies on the design, modeling and optimization of solid desiccant wheels. In the desiccant wheels, it is very difficult to model the process mathematically because heat and mass transfer realize simultaneously. Jurinak [8] developed a simple model to overcome this difficulty and this model is used by many researchers. However, this model has a structure that can be used for limited working conditions (especially high air flow rate). In this study, based on Jurinak's model, a model was developed for a solid desiccant wheel which can be used under different working conditions in applications where low air flow rate is required. The results of the model have been tested by comparing with the manufacturer data. At the end of the study, it is found that the results obtained from the developed model were in good agreement with the manufacturer's data and the model was suitable for using at different working conditions.
\end{abstract}

Keywords: Dehumidification, Solid desiccant, Wheel, Modelling

*Sorumlu yazar (Corresponding author): Ertaç HÜRDOĞAN, ehurdogan@osmaniye.edu.tr 


\section{GíRiş}

Günümüzde enerji tüketiminin önemli bir miktarını, binaların hem 1sitma hem de soğutmasında kullanılan iklimlendirme prosesleri oluşturmaktadır [1]. İklimlendirme sistemleri, bir ortamın konfor şartlarının elde edilmesinde kullanılan sistemlerdir [2]. İnsanoğlunun yaz şartlarında istenilen konfor şartlarını elde etmek için kullandığı metotların en eskilerinden birisi de evaporatif soğutma sistemleridir. Evaporatif soğutma sisteminde temel prensip, ortamın duyulur 1sısını gizli 1sıya dönüştürerek ortamın sıcaklığını düşürmektir [3]. Özellikle sıcak ve nemli bölgelerde konut, ticari yada ofis binalarında 1sıl konforun sağlanması için, evaporatif soğutma tekniklerinin kullanımı elektriksel güç tüketimini arttırmakta ve bu durum da sistemin kullanımının yeteri kadar efektif olmadığını göstermektedir $[2,4]$. Sicak ve nemli iklimlerde nem almalı (desisif) soğutma sistemlerinin kullanımı evaporatif soğutma sistemlerine kıyasla daha uygun bir seçenek olarak önerilmektedir [4]. Nem alıcı materyaller katı ve sıvı olmak üzere ikiye ayrılmaktadırlar [5-7]. Nem almalı soğutma sistemlerinde katı nem alıcı rotor (teker) kullanımının gün geçtikçe popülerliği artmaktadır. $\mathrm{Bu}$ sistemlerde, çevre havası ve nem alıcıların yüzeyi arasında meydana gelen su buhar basinc1 farkından dolayı nem alıcı madde su buharını absorbe etmektedir [1]. Nem alıcı rotorların iklimlendirme sistemlerinde yaygın olarak kullanılmasından dolayı çoğu araştırmacı nem alıcı rotorların tasarımı, modellenmesi ve optimizasyonu üzerine çalışmalar gerçekleştirmişlerdir. Jurinak [8] ve Howe [9], nem alıcı rotorun çıkış şartlarını tanımlayan basit bir model geliştirmişlerdir. $\mathrm{Bu}$ modelde, silika-jel için iki karakteristik potansiyel $\left(F_{1}\right.$ ve $\left.F_{2}\right)$ ve verimlilik faktörleri $\left(\eta_{1}\right.$ ve $\left.\eta_{2}\right)$ kullanılarak nem alıcı rotorun proses kanalından çıkan havanın sıcaklık ve mutlak nem değerleri bulunabilmektedir. White ve arkadaşları [10], süper adsorbent polimer ve zeolite'den oluşan iki yeni nem alıci rotorun performansinı kıyaslamışlardır. Yazarlar düşük rejenerasyon sicaklıklarında süper adsorbent polimer malzemesinden yapılan nem alıcı rotorun daha fazla nem çekme kapasitesine sahip olduğu sonucuna ulaşmışlardır. Stabat ve Marchio [11], nem alıcı rotorun davranışını belirlemek için bir model geliştirmişlerdir. Yazarlar geliştirdikleri modelin, çalışma koşulları içerisinde ekipmanın karakterize edilebilmesi, doğruluk ve ölçülebilirliğin kolaylaştırılması gibi birçok kriteri karşıladığını belirtmişlerdir. Çalışma sonunda, modelden elde ettikleri tahmini sonuçları deneysel ve üretici veriler ile kıyaslamışlar ve modelin kullanılabilirliğini göstermişlerdir. Panaras ve arkadaşları [12], Jurinak tarafindan geliştirilen modeli baz alarak, nem alıcı rotorun modellenmesi için farklı yaklaşımlar kullanmışlardır. Çalışmada $6 \mathrm{dev}$./saat rotor hizında, 600, 1000 ve 1200 $\mathrm{m}^{3}$ /saat olacak şekilde üç farklı debi için verimlilik faktörleri $\left(\eta_{1}\right.$ ve $\left.\eta_{2}\right)$ belirlenmiş ve elde edilen sonuçlar, deneysel veriler ve üretici verileri ile kıyaslanmıştır. Joudi ve Dhaidan [13] 1sıtma ve nem almalı soğutma sistemlerin performansını Bağdat'da yer alan bir bina için değerlendirmişlerdir. Yazarlar farklı çalışma koşulları ve tasarımların sistemin ve ekipmanlarının performansı üzerine etkisini değerlendirmek için bir bilgisayar simülasyonu geliştirmişlerdir. Çalışmada nem almalı rotorun modellenmesinde Jurinak'ın çalışması baz alınmıştır. Sonuç olarak yapılan simülasyon çalışmasında ortam sicaklığı, rejenerasyon sıcaklığg1, 1sı değiştiricisi etkinliği, ve evaporatif soğutma etkinliğinin sistem performansına önemli etkisi olduğu görülmüştür. Nia ve arkadaşları [14], iklimlendirme ve havalandırma sistemleri için kullanılan nem alıcı rotorun modellenmesi üzerine bir çalışma gerçekleştirmişlerdir. Simülasyon çalışmasında, MATLAB Simulink yazılımından faydalanmışlardır. Bu çalışmada, sayısal metot kullanılarak adyabatik nem alıcı rotorun performansı ve optimum rotor hızı belirlenmiştir. Beccali ve arkadaşları [15] katı nem alıcı rotorun performansını değerlendirebilmek için basit bir model geliştirmişlerdir. Modelin oluşumunda üretici verilerinden faydalanmışlardır. Sonuç olarak araştırmacılar geliștirmiş oldukları modelin basit ve üç farklı nem alıcı rotorun performansının belirlenmesi için uygun olduğundan bahsetmişlerdir.

Katı nem alıcı rotorda, 1sı ve kütle transferi birlikte gerçekleştiğinden prosesi matematiksel olarak modellemek çok zor bir işlemdir. Bu zorluğun 
giderilmesi üzerine Jurinak [8] basit bir model geliştirmiş ve literatürde birçok bilim adamı bu modelin kullanımı ve geliştirilmesi üzerine çalışmalar yürütmüşlerdir. İlgili çalışmalar, Jurinak'1n önerdiği verimlilik faktörleri, rotorun nem alma kapasitesine $[13,16]$ ve çalışma debisine [12] göre sabit değerler alınarak gerçekleştirilmiştir. Dolayısıyla kullanılan veya geliştirilen modellerin geçerliliği sadece çalışılan parametreler ve şartlar için uygundur. Ayrıca bu çalışmaların çoğunda oluşturulan modellerin geçerliliği sadece, ele alınan nem alıcı rotorların yüksek hava debisi ile çalışması durumunda kullanımıyla sınırlıdır.

$\mathrm{Bu}$ çalışmada, düşük hava ihtiyacının ( $\left.\leq 600 \quad \mathrm{~m}^{3} / \mathrm{saat}\right) \quad$ olduğu uygulamalarda kullanılabilecek katı nem alıcı bir rotorun, farklı debi ve rejenerasyon sıcaklıkları çalışma şartları altında proses kanalından çıkan havanın sıcaklık ve mutlak nem değerlerinin hesaplanabilmesi için Jurinak'ın modeli baz alınarak bir model geliştirilmiştir. Burada, Jurinak'ın verimlilik faktörleri, hacimsel debinin $(\dot{V})$ ve karakteristik potansiyellerin $\left(F_{1}\right.$ ve $\left.F_{2}\right)$ bir fonksiyonu olarak modellenmiştir. Böylece farklı çalışma şartları için verimlilik faktörü belirlenebilmekte ve katı nem alıcı rotorun proses kanalından çıkan havanın şartları hesaplanabilmektedir. $\mathrm{Bu}$ modelin geliştirilmesinde üretici verilerinden [17] faydalanılmış ve analizlerde MATLAB yazılımı kullanılmıştır.

\section{MODELLEME ÇALIŞMASI}

Şekil 1'de model çalıșmalarında ele alınan katı nem alıcı rotorun şematik resmi verilmiştir. Şekilden de görüldüğü üzere, katı nem alıc rotorların kullanıldığ 1 sistemlerde iki hava kanalı bulunmaktadır. Bunlardan birisi taze havanın sistemde dolaştığ 1 proses kanalı $(1 \rightarrow 2)$, diğeri ise rejenerasyon kanalıdır $(3 \rightarrow 4)$. Katı nem alıcı rotor proses kanalındaki taze havanın neminin uzaklaştırılması amacıyla kullanılmaktadır. Nem alıcı rotora 1 noktasından giren nemli hava, rotordan geçerken nemi düşürülmekte ve 2 noktasında kuru ve daha sicak olacak şekilde rotordan çıkmaktadır. Aynı anda belli bir debiye sahip sicak hava (rejenerasyon havasi) 3 noktasından ters yönden katı nem alıcı rotora gönderilmekte ve proses kanalındaki havadan çekilen nemi üzerine alarak 4 noktasında sistemden uzaklaşmaktadır [18].

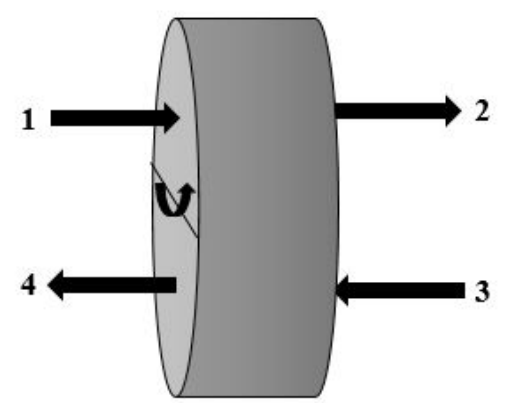

Şekil 1. Katı nem alıcı rotorun şematik diyagramı; 1: proses giriş, 2: proses çıkış,

3: rejenerasyon giriş, 4 :rejenerasyon çıkış

Nem alıcı rotorda proses kanalından çıkan havanın (Şekil 1, 2 noktası) sicaklık $\left(\mathrm{T}_{2}\right)$ ve mutlak nemini $\left(\mathrm{W}_{2}\right)$ belirleyebilmek için Jurinak tarafindan basit bir yaklaşım geliştirilmiştir [8]. Bu yaklaşıma göre, nem alıcı rotorda proses kanalından çıkan havanın şartlarını belirleyebilmek için verimlilik faktörleri ( $\eta_{F 1}$ ve $\eta_{F 2}$ ) ile birlikte mutlak nem ve sıcaklığa bağlı olarak oluşturulan $F_{1}$ ve $F_{2}$ karakteristik potansiyellerinin bilinmesi gerekmektedir. Silica-jel ve hava-su buharının karakteristik potansiyelleri olarak ifade edilen $\mathrm{F}_{1}$ ve $F_{2}$ değerlerini belirleyebilmek için sıcaklık ve mutlak neme bağlı olarak bir eğri uydurulmuştur. Elde edilen $F_{1}$ ve $F_{2}$ karakteristik potansiyelleri ve $\eta_{\mathrm{F} 1}$ ve $\eta_{\mathrm{F} 2}$ verimlilik faktörleri kullanılarak $T_{2}$ ve $\mathrm{W}_{2}$ hesaplanabilmektedir. Jurinak'ın yaklaşımında kullanılan değişkenlere ait Eşitlik 1-4'de verilmiştir $[8,12]$ :

$$
\begin{aligned}
& F_{1, i}=\frac{-2865}{\left(T_{i}+273,15\right)^{1,49}}+4,344 \cdot\left(\frac{W_{i}}{1000}\right)^{0,8624} \\
& F_{2, i}=\frac{\left(T_{i}+273,15\right)^{1,49}}{6360}-1,127 \cdot\left(\frac{W_{i}}{1000}\right)^{0,07969} \\
& \eta_{F 1}=\frac{F_{1,2}-F_{1,1}}{F_{1,3}-F_{1,1}} \\
& \eta_{F 2}=\frac{F_{2,2}-F_{2,1}}{F_{2,3}-F_{2,1}}
\end{aligned}
$$


Burada, $F_{1,1}$ ve $F_{2,1}$ nem alic1 rotora proses kanalından giren havanın (1 noktası) karakteristik potansiyelleridir. $F_{1,2}$ ve $F_{2,2}$ nem alic1 rotorda proses kanalından çıkan havanın (2 noktası) karakteristik potansiyelleridir. $F_{1,3}$ ve $F_{2,3}$ nem alıc1 rotora rejenerasyon kanalından giren havanın (3 noktasi) karakteristik potansiyelleridir. $\eta_{F 1}$ ve $\eta_{\mathrm{F} 2}$ nem alıc1 rotorun verimlilik faktörleridir. Literatürde Jurinak'ın yaklaşımı kullanılarak yapılan çalışmalarda, $\eta_{\mathrm{F} 1}$ ve $\eta_{\mathrm{F} 2}$ nem alıc1 rotorun verimlilik faktörlerine belirli debiler için sabit değerler verilerek (değişken debiler için uygun değil) çözümlemeler yapılmıştır [12,13,16].

$\mathrm{Bu}$ çalışmada değişken debi, proses ve rejenerasyon giriş havası sıcaklık ve mutlak nem değerleri göz önünde bulundurularak, $\eta_{\mathrm{F} 1}$ ve $\eta_{\mathrm{F} 2}$ verimlilik faktörleri için eşitlikler geliştirilmiştir. Çalışmada nem alıcı rotorun proses havası ve rejenerasyon havasının debileri eşit ve rotor üzerinde aynı kesit alandan geçtiği $(\mathrm{R} / \mathrm{P}=1)$ kabul edilmiştir. Eşitlikler geliştirilirken değişken debi ve rejenerasyon sicaklıklarında çalışılmıştır. Çalışma kapsamında elde edilecek $\eta_{\mathrm{F} 1}$ ve $\eta_{\mathrm{F} 2}$ eşitliklerinin üretici verilerine daha iyi yakınsaması için, hesaplamalar, proses kanalına giren hava sıcaklığının iki farklı aralıkta olması durumu için ayrı ayrı yapılmıştır. $\mathrm{Bu}$ aralıkların birincisi (düşük sıcaklıklar, DS) kurutma uygulamaları ve kış iklim şartları düşünülerek 5-20 ${ }^{\circ} \mathrm{C}$, ikincisi ise (yüksek sıcaklıklar, YS) yaz şartları düşünülerek $25-40{ }^{\circ} \mathrm{C}$ arasında olacak şekilde belirlenmiştir. Çizelge 1'de eşitliklerin üretilmesinde kullanılan çalışma koşulları verilmiştir.

Çizelge 1. Nem alıcı rotorun çalışma koşulları

\begin{tabular}{|l|c|c|}
\hline Parametre & Birim & $\begin{array}{c}\text { Çalışma } \\
\text { Koşulları }\end{array}$ \\
\hline Hacimsel Debi $(\dot{V})$ & $\mathrm{m}^{3} / \mathrm{saat}$ & $150,300,450,600$ \\
\hline $\begin{array}{l}\text { Rejenerasyon Giriş } \\
\text { Sicaklığı }\left(\mathrm{T}_{3}\right)\end{array}$ & ${ }^{\circ} \mathrm{C}$ & $70,80,90$ \\
\hline $\begin{array}{l}\text { Rejenerasyon Giriş } \\
\text { Mutlak Nemi }\left(\mathrm{W}_{3}\right)\end{array}$ & $\mathrm{g}_{\mathrm{su}} / \mathrm{kg}_{\mathrm{kh}}$ & $4-25$ \\
\hline $\begin{array}{l}\text { Proses Giriş Sıcaklığı-DS } \\
\left(\mathrm{T}_{1-\mathrm{DS}}\right)\end{array}$ & ${ }^{\circ} \mathrm{C}$ & $5-20$ \\
\hline $\begin{array}{l}\text { Proses Giriş Sıcaklı̆̆ı-YS } \\
\left(\mathrm{T}_{1-\mathrm{Ys}}\right)\end{array}$ & ${ }^{\circ} \mathrm{C}$ & $25-40$ \\
\hline $\begin{array}{l}\text { Proses Giriş Mutlak Nemi } \\
\left(\mathrm{W}_{1}\right)\end{array}$ & $\mathrm{g}_{\mathrm{su}} / \mathrm{kg}_{\mathrm{kh}}$ & $5-25$ \\
\hline Rotor Hızı & $\mathrm{dev} / \mathrm{saat}$ & 12 \\
\hline
\end{tabular}

Çalışmada ayrıca eşitlikler üretilirken, proses ve rejenerasyon kanalından giren havanın sicaklık ve mutlak nem değerlerinin de etkisini hesaba katmak için karakteristik potansiyel farklarından $\left(\Delta \mathrm{F}_{1}, \Delta \mathrm{F}_{2}\right)$ faydalanılmıştır. $\Delta \mathrm{F}_{1}$ ve $\Delta \mathrm{F}_{2}$ aşağıdaki Eşitlik 5 ve 6 kullanılarak belirlenmiştir.

$\Delta \mathrm{F}_{1}=\mathrm{F}_{1,3}-\mathrm{F}_{1,1}$

$\Delta \mathrm{F}_{2}=\mathrm{F}_{2,3}-\mathrm{F}_{2,1}$

$\mathrm{Bu}$ çalışma kapsamında geliştirilen modelin kullanılabilirliğini test etmek için doğruluk kriterleri olan Ortalama Hata Karekökü (Root Mean Square Error, RMSE) ve Ortalama Mutlak Hata (Mean Absolute Error, MAE) değerlerine bakılmıştır. Doğruluk kriterlerinin hesaplanmasında kullanılan eşitlikler [19] Çizelge 2'de verilmiştir.

Çizelge 2. Doğruluk kriterlerinin eşitlikleri [19]

\begin{tabular}{|l|c|l|}
\hline $\begin{array}{l}\text { Doğruluk } \\
\text { Kriteri }\end{array}$ & Eşitlik & Parametreler \\
\hline RMSE & $\sqrt{\frac{\left(\mathrm{S}_{1}-\mathrm{G}_{1}\right)^{2}+\cdots+\left(\mathrm{S}_{\mathrm{n}}-\mathrm{G}_{\mathrm{n}}\right)^{2}}{\mathrm{n}}}$ & $\begin{array}{l}\text { S:Sayısal } \\
\text { Değer } \\
\text { G:Gerçek } \\
\text { Değer } \\
\text { n:Veri Sayıs1 }\end{array}$ \\
\hline MAE & $\frac{\left|\mathrm{S}_{1}-\mathrm{G}_{1}\right|+\cdots\left|\mathrm{S}_{\mathrm{n}}-\mathrm{G}_{\mathrm{n}}\right|}{\mathrm{n}}$ & $\begin{array}{l}\text { S:Sayısal } \\
\text { Değer } \\
\text { G:Gerçek } \\
\text { Değer } \\
\text { n:Veri Sayı1s1 }\end{array}$ \\
\hline
\end{tabular}

\section{SONUÇLAR VE TARTIŞMA}

Bu çalışmada, katı nem alıcı bir rotorun farklı debi ve rejenerasyon sıcaklıkları için proses kanalındaki $\mathrm{T}_{2}$ ve $\mathrm{W}_{2}$ değerlerinin basit bir şekilde hesaplanabilmesi ve farklı çalışmalarda kullanılabilmesi için Jurinak'ın modeli [8] baz alınarak bir model geliştirilmiştir. Jurinak'ın modelinde nem alıcı rotorda $\mathrm{T}_{2}$ ve $\mathrm{W}_{2}$ değerlerinin bilinmesi için $\eta_{F 1}$ ve $\eta_{F 2}$ verimlilik faktörleri kullanılmaktadır. Literatürde bu faktörler genelde çalışılan aralıklar için sabit değerler almaktadır. Bu çalışmada $\eta_{\mathrm{F} 1}$ ve $\eta_{\mathrm{F} 2}$ verimlilik faktörleri, değişken debi ve rejenerasyon sıcaklıklarında $\left(\mathrm{T}_{3}\right)$, proses ve rejenerasyon kanalından farklı giriş şartları göz önünde bulundurularak belirlenmiştir. Katı nem alıcı rotorun çıkışındaki havanın model ile hesaplanan şartlarının, üretici verilerine daha 
yakın doğrulukta olabilmesi için, proses kanalına giren havanın iki farklı sıcaklık aralığında $\left(5-20^{\circ} \mathrm{C}\right.$ ve $25-40^{\circ} \mathrm{C}$ ) olma durumu değerlendirilerek model oluşturulmuştur.

Şekil 2-a, b, c ve d'de sırasıyla nem alıcı rotora giren havanın düşük ve yüksek sıcaklıklar aralığında olma durumunda üretici verileri ve Eşitlik 3 ve 4 kullanılarak hesaplanan $\eta_{\mathrm{F} 1}$ ve $\eta_{\mathrm{F} 2}$ verimlilik faktörlerinin debi $(\dot{V})$ ve karakteristik potansiyel farklar $\left(\Delta \mathrm{F}_{1}\right.$ ve $\left.\Delta \mathrm{F}_{2}\right)$ ile değişimleri gösterilmiştir. $\mathrm{Bu}$ veriler kullanılarak $\mathrm{DS}$ ve YS için $\eta_{F 1}$ ve $\eta_{F 2}$ polinomsal eşitlikleri, debi ve karakteristik potansiyel farkların fonksiyonu olarak üretilmiştir (Eşitlik 7-10). Düşük sıcaklıklar için üretilen verimlilik faktörleri ( $\eta_{\mathrm{F} 1, \mathrm{DS}}$ ve $\eta_{\mathrm{F} 2, \mathrm{DS}}$ ) Eşitlik 7 ve 8'de, yüksek sicaklıklar için üretilen verimlilik faktörleri ( $\eta_{\mathrm{F} 1, \mathrm{YS}}$ ve $\left.\eta_{\mathrm{F} 2, \mathrm{YS}}\right)$ ise Eşitlik 9 ve 10'da verilmiştir. Eşitliklerdeki sabit katsayılar Çizelge 3'de yer almaktadır.

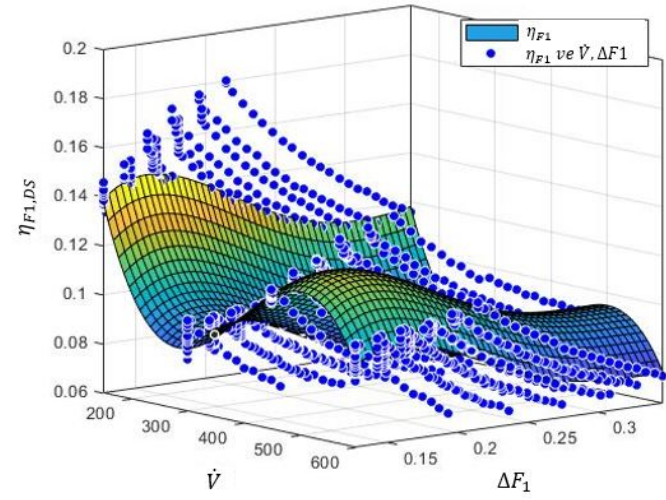

(a)

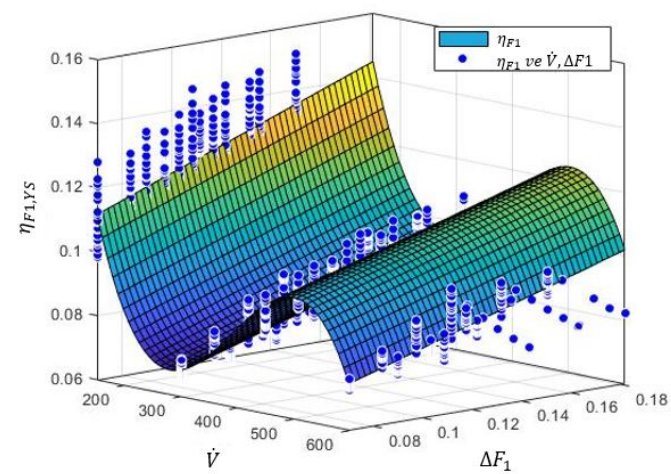

(c)

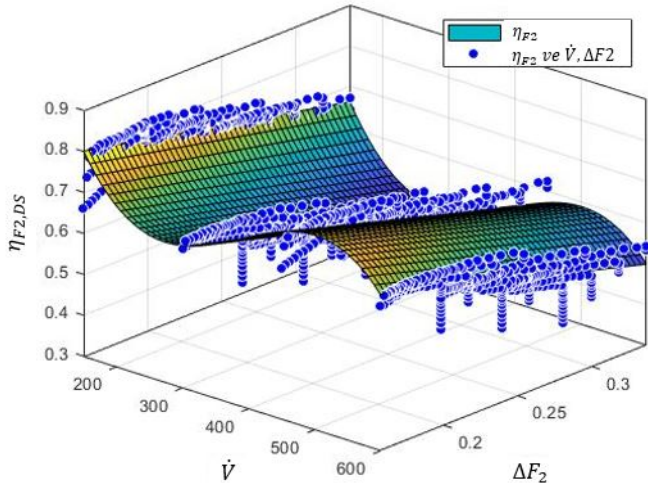

(b)

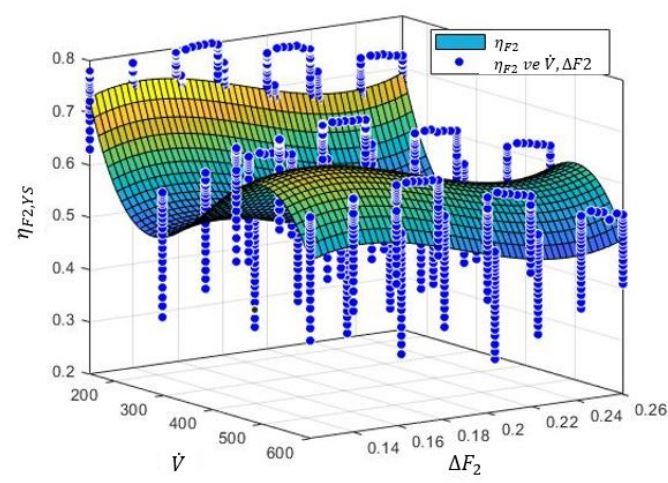

(d)

Şekil 2. Düşük (a ve b) ve yüksek (c ve d) sıcaklık için verimlilik faktörlerinin debi ve karakteristik potansiyel farkları ile değişimi

$\eta_{\mathrm{F} 1, \mathrm{DS}}=\mathrm{a} 1+\mathrm{a} 2 \cdot \dot{\mathrm{V}}+\mathrm{a} 3 \cdot \Delta \mathrm{F}_{1}+\mathrm{a} 4 \cdot \dot{\mathrm{V}}^{2}+\mathrm{a} 5 \cdot \dot{\mathrm{V}} \cdot \Delta \mathrm{F}_{1}+\mathrm{a} 6 \cdot \Delta \mathrm{F}_{1}{ }^{2}+\mathrm{a} 7 \cdot \dot{\mathrm{V}}^{3}+\mathrm{a} 8 \cdot \dot{\mathrm{V}}^{2} \cdot \Delta \mathrm{F}_{1}+\mathrm{a} 9 \cdot \dot{\mathrm{V}} \cdot \Delta \mathrm{F}_{1}{ }^{2}+$

$\mathrm{a} 10 \cdot \Delta \mathrm{F}_{1}{ }^{3}+\mathrm{a} 11 \cdot \dot{\mathrm{V}}^{3} \cdot \Delta \mathrm{F}_{1}+\mathrm{a} 12 \cdot \dot{\mathrm{V}}^{2} \cdot \Delta \mathrm{F}_{1}{ }^{2}+\mathrm{a} 13 \cdot \dot{\mathrm{V}} \cdot \Delta \mathrm{F}_{1}{ }^{3}+\mathrm{a} 14 \cdot \Delta \mathrm{F}_{1}{ }^{4}$

$\eta_{\mathrm{F} 2, \mathrm{DS}}=\mathrm{b} 1+\mathrm{b} 2 \cdot \dot{\mathrm{V}}+\mathrm{b} 3 \cdot \Delta \mathrm{F}_{2}+\mathrm{b} 4 \cdot \dot{\mathrm{V}}^{2}+\mathrm{b} 5 \cdot \dot{\mathrm{V}} \cdot \Delta \mathrm{F}_{2}+\mathrm{b} 6 \cdot \dot{\mathrm{V}}^{3}+\mathrm{b} 7 \cdot \dot{\mathrm{V}}^{2} \cdot \Delta \mathrm{F}_{2}$ 


$$
\begin{aligned}
& \eta_{\mathrm{F} 1, \mathrm{YS}}=\mathrm{c} 1+\mathrm{c} 2 \cdot \dot{\mathrm{V}}+\mathrm{c} 3 \cdot \Delta \mathrm{F}_{1}+\mathrm{c} 4 \cdot \dot{\mathrm{V}}^{2}+\mathrm{c} 5 \cdot \dot{\mathrm{V}} \cdot \Delta \mathrm{F}_{1}+\mathrm{c} 6 \cdot \dot{\mathrm{V}}^{3}+\mathrm{c} 7 \cdot \dot{\mathrm{V}}^{2} \cdot \Delta \mathrm{F}_{1} \\
& \eta_{\mathrm{F} 2, \mathrm{YS}}=\mathrm{d} 1+\mathrm{d} 2 \cdot \dot{\mathrm{V}}+\mathrm{d} 3 \cdot \Delta \mathrm{F}_{2}+\mathrm{d} 4 \cdot \dot{\mathrm{V}}^{2}+\mathrm{d} 5 \cdot \dot{\mathrm{V}} \cdot \Delta \mathrm{F}_{2}+\mathrm{d} 6 \cdot \Delta \mathrm{F}_{2}{ }^{2}+\mathrm{d} 7 \cdot \dot{\mathrm{V}}^{3}+\mathrm{d} 8 \cdot \dot{\mathrm{V}}^{2} \cdot \Delta \mathrm{F}_{2}+\mathrm{d} 9 \cdot \dot{\mathrm{V}} \cdot \Delta \mathrm{F}_{2}{ }^{2}+\mathrm{d} 10 \cdot \Delta \mathrm{F}_{2}{ }^{3}
\end{aligned}
$$

Çizelge 3. Polinomsal eşitliklerdeki sabit katsayı değerleri

$$
\begin{aligned}
& \text { Eşitlik } 7 \quad \mathrm{a} 1=0,03235, \mathrm{a} 2=-0,002886, \mathrm{a} 3=6,734, \mathrm{a} 4=8,204 \times 10^{-6}, \mathrm{a} 5=0,0004009, \mathrm{a} 6=-41,55, \mathrm{a} 7=-6,929 \times 10^{-09}, \\
& \mathrm{a} 8=-5,047 \times 10^{-06}, \mathrm{a} 9=0,006358, \mathrm{a} 10=101,8, \mathrm{a} 11=4,071 \times 10^{-09}, \mathrm{a} 12=7,24 \times 10^{-07}, \mathrm{a} 13=-0,01002, \mathrm{a} 14=-87,73, \\
& \text { Eşitlik } 8 \quad \mathrm{~b} 1=1,744, \mathrm{~b} 2=-0,00882, \mathrm{~b} 3=-0,4722, \mathrm{~b} 4=2,556 \times 10^{-05}, \mathrm{~b} 5=-0,002296, \mathrm{~b} 6=-2,227 \times 10^{-08}, \mathrm{~b} 7=2,299 \times 10^{-06} \\
& \text { Eşitlik } 9 \mathrm{c} 1=0,3118, \mathrm{c} 2=-0,002328, \mathrm{c} 3=0,3697, \mathrm{c} 4=6,545 \times 10^{-06}, \mathrm{c} 5=-0,0005717, \mathrm{c} 6=-5,618 \times 10^{-09}, \mathrm{c} 7=6,065 \times 10^{-07} \\
& \text { Eşitlik } 10 \mathrm{~d} 1=0,7327, \mathrm{~d} 2=-0,01225, \mathrm{~d} 3=20,69, \mathrm{~d} 4=3,406 \times 10^{-05}, \mathrm{~d} 5=-0,0001866, \mathrm{~d} 6=-115,6, \mathrm{~d} 7=-2,902 \times 10^{-08}, \\
& \mathrm{~d} 8=3,445 \times 10^{-07}, \mathrm{~d} 9=-0,0004209, \mathrm{~d} 10=203,2
\end{aligned}
$$

Çizelge 4'de sırasıyla düşük ve yüksek s1caklıklarda $\eta_{\mathrm{F} 1}$ ve $\eta_{\mathrm{F} 2}$ verimlilik faktörlerinin hesaplanması için geliştirilen modellerin doğruluk kriterleri olan RMSE ve MAE sonuçları verilmiştir. RMSE ve MAE değerlerinin düşük olması verimlilik faktörlerini hesaplayan bu eşitliklerin kullanılabilirliğini göstermektedir.

Çizelge 4. DS ve YS için elde edilen verimlilik faktörlerinin $\left(\eta_{\mathrm{F} 1}\right.$ ve $\left.\eta_{\mathrm{F} 2}\right)$ RMSE değerleri

\begin{tabular}{|c|c|c|}
\hline Parametre & RMSE & MAE \\
\hline$\eta_{\mathrm{F} 1, \mathrm{DS}}$ & 0,004721 & 0,008668 \\
\hline$\eta_{\mathrm{F} 2, \mathrm{DS}}$ & 0,007660 & 0,025885 \\
\hline$\eta_{\mathrm{F} 1, \mathrm{YS}}$ & 0,001447 & 0,004611 \\
\hline$\eta_{\mathrm{F} 2, \mathrm{YS}}$ & 0,071010 & 0,057195 \\
\hline
\end{tabular}

Çalışma kapsamında son olarak geliştirilen modelden elde edilen sonuçlar ile üretici verileri kıyaslanmıştır. Şekil $3,4,5$ ve 6 'da sırasıyla 150 , 300,450 ve $600 \mathrm{~m}^{3} / \mathrm{saat}$ debide farklı giriş şartlarına göre, geliştirilen model (sayısal çözümleme) ve üretici verileri ile elde edilen proses havası çıkış sıcaklık ( $\left.\mathrm{T}_{2-\mathrm{DS}}, \mathrm{T}_{2-\mathrm{YS}}\right)$ ve mutlak nem değerleri ( $\left.\mathrm{W}_{2-\mathrm{DS}}, \mathrm{W}_{2-\mathrm{Ys}}\right)$ verilmiştir. Toplamda model ve üretici verileri ile elde edilen 2067 sıcaklık çıktı verisi ve 2067 mutlak nem çıktı verisi kıyaslamıştır. Şekillerden de görüldüğü gibi aynı giriş şartlarında model ile elde edilen veriler, üretici verileri ile iyi bir uyum içerisindedir. Şekil 7'de, tüm debiler için sırasıyla düşük (a ve b) ve yüksek (c ve d) sıcaklık şartlarında nem alıcı rotordan çıkan havanın geliştirilen model ve üretici verileri ile elde edilen sicaklik ve mutlak nem değerlerinin kıyaslaması yapılmıştır. Katı nem alıcı rotora giren havanın, düşük sıcaklık aralığında olma durumu için elde edilen eşitliklerin, yüksek sıcaklık aralığında olma durumu için elde edilen eşitliklere kıyasla daha iyi sonuçlar verdiği gözlemlenmiştir.

Çizelge 5'de DS ve YS için hesaplanan $\mathrm{T}_{2}$ ve $\mathrm{W}_{2}$ değerlerinin doğruluk kriterleri olan RMSE ve MAE sonuçları verilmiştir. Tablodan görüldüğü gibi oluşturulan modelin doğruluk kriterleri düşük değerler almıştır. Bu durum geliştirilen modelin, her iki sıcaklık aralığı için kullanılabilir olduğunu göstermektedir.

Çizelge 5. DS ve YS için model ile elde edilen $\mathrm{T}_{2}$ ve $\mathrm{W}_{2}$ değerlerinin doğruluk kriterleri

\begin{tabular}{|c|c|c|}
\hline Parametre & RMSE & MAE \\
\hline $\mathrm{T}_{2-\mathrm{DS}}$ & 0,9246 & 0,7350 \\
\hline $\mathrm{W}_{2-\mathrm{DS}}$ & 0,2388 & 0,1828 \\
\hline $\mathrm{T}_{2-\mathrm{YS}}$ & 1,8934 & 1,5509 \\
\hline $\mathrm{W}_{2-\mathrm{YS}}$ & 0,6441 & 0,5220 \\
\hline
\end{tabular}




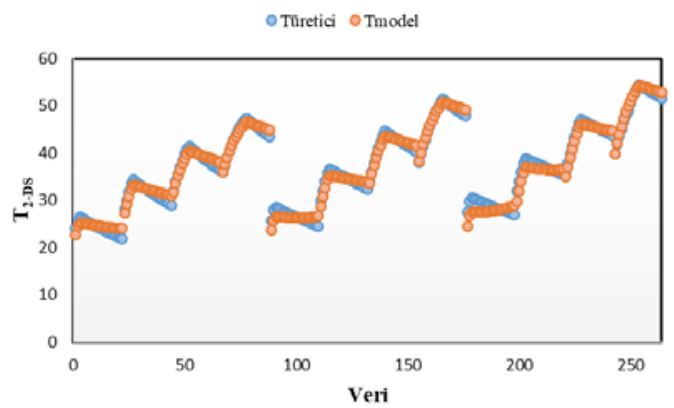

(a)

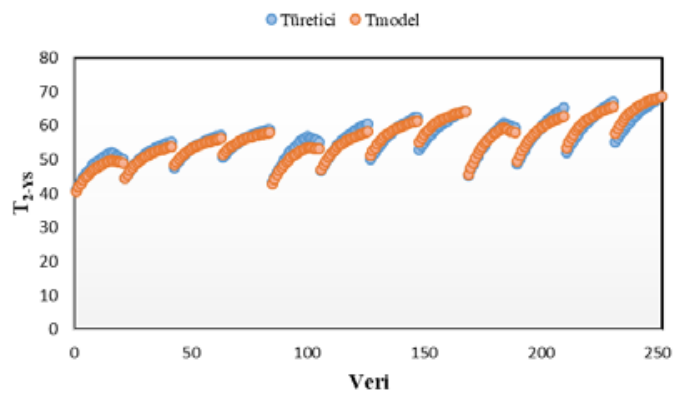

(c)

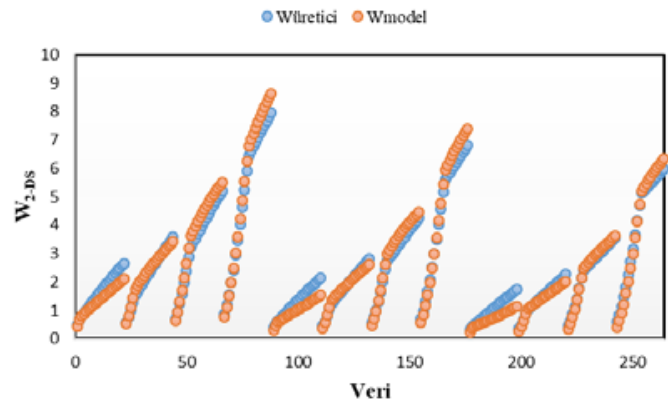

(b)

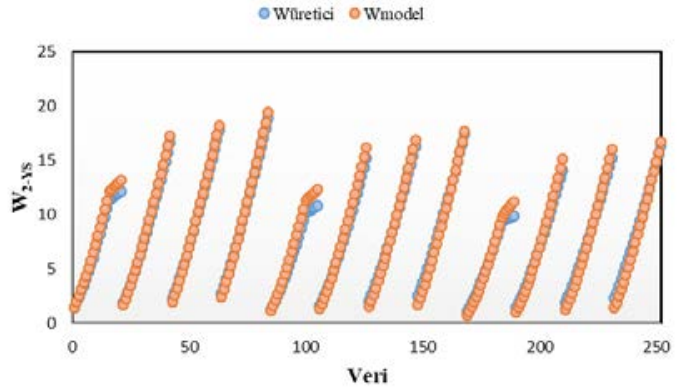

(d)

Şekil 3. $150 \mathrm{~m}^{3} / \mathrm{saat}$ debi için farklı giriş şartlarına göre, geliştirilen model ve üretici verilerinin karşılaştırılması

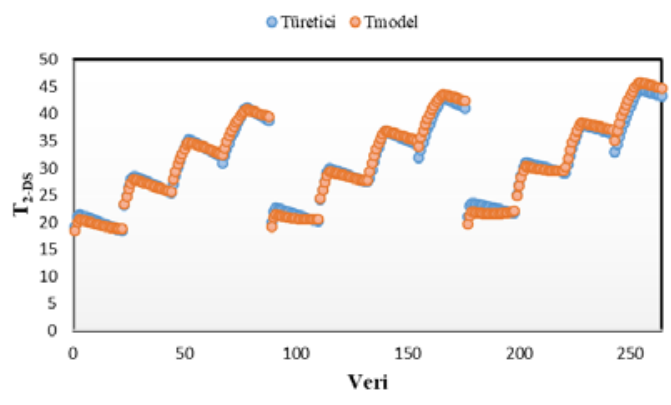

(a)

- Türetici OTmode

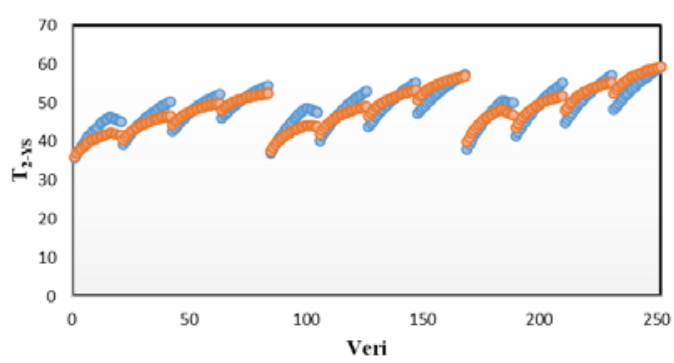

(c)

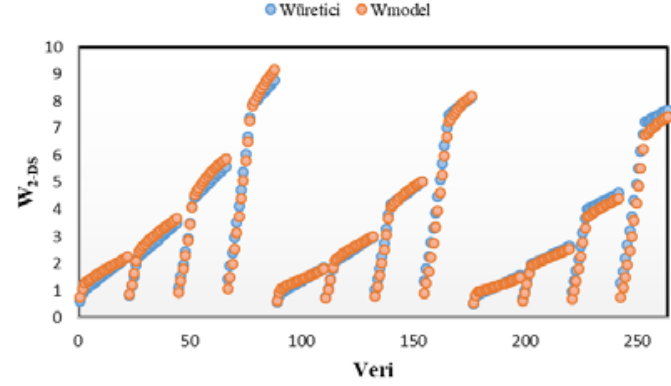

(b)

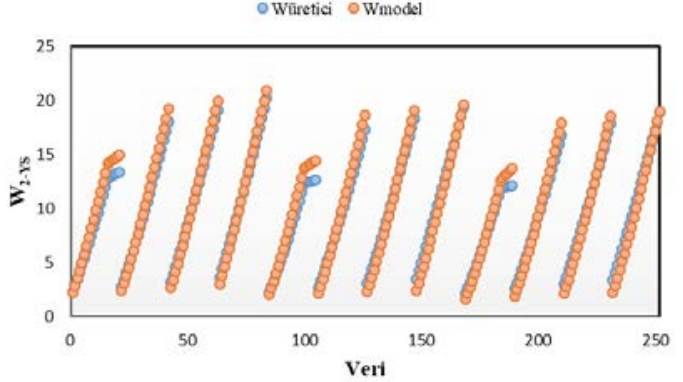

(d)

Şekil 4. $300 \mathrm{~m}^{3}$ /saat debi için farklı giriş şartlarına göre, geliştirilen model ve üretici verilerinin karşılaştırılması 


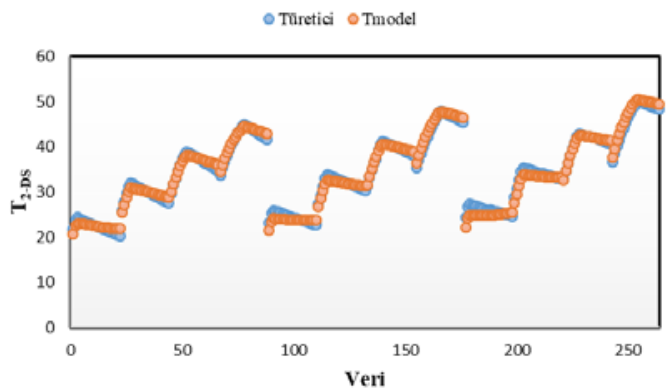

(a)

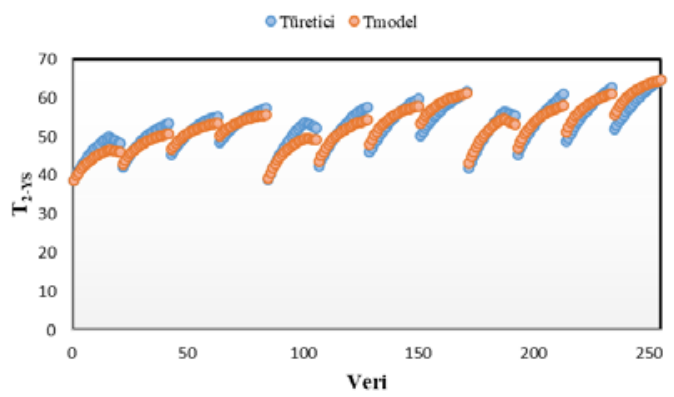

(c)

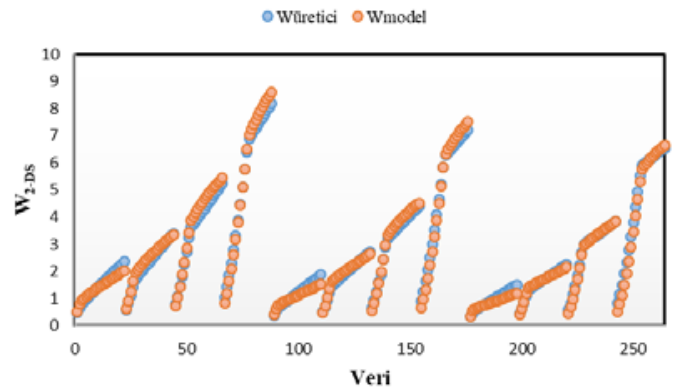

(b)

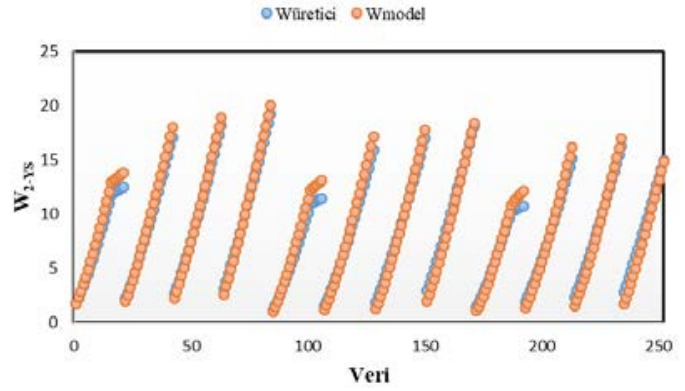

(d)

Şekil 5. $450 \mathrm{~m}^{3}$ /saat debi için farklı giriş şartlarına göre, geliştirilen model ve üretici verilerinin karşılaştırılması

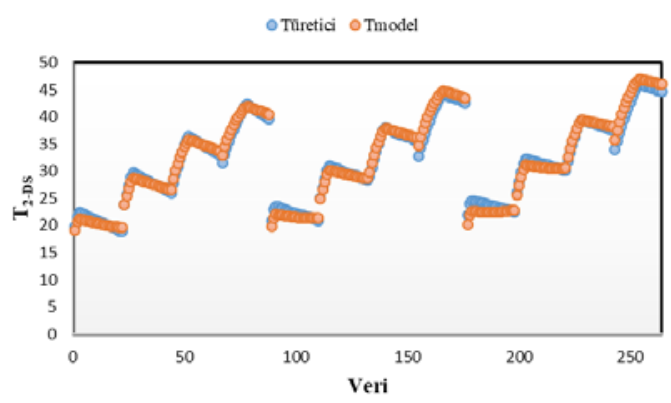

(a)

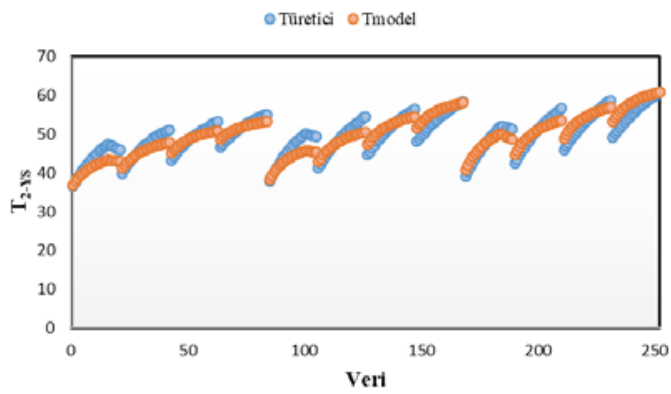

(c)

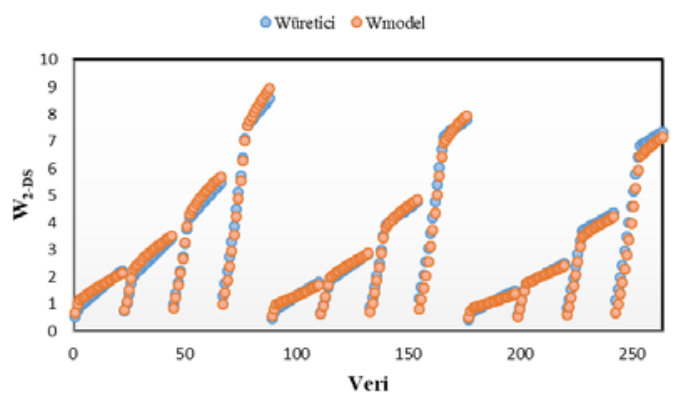

(b)

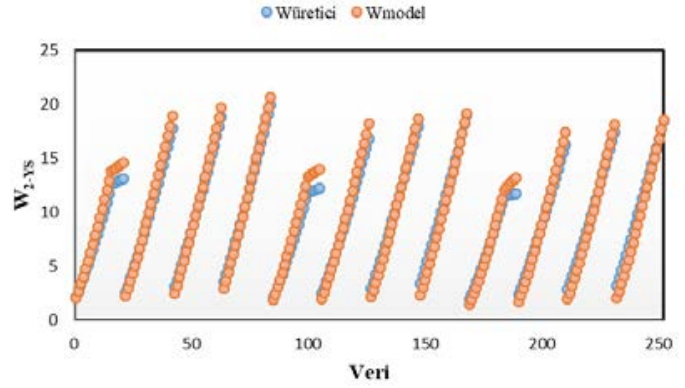

(d)

Şekil 6. $600 \mathrm{~m}^{3} / \mathrm{saat}$ debi için farklı giriş şartlarına göre, geliştirilen model ve üretici verilerinin karşılaştırılması 


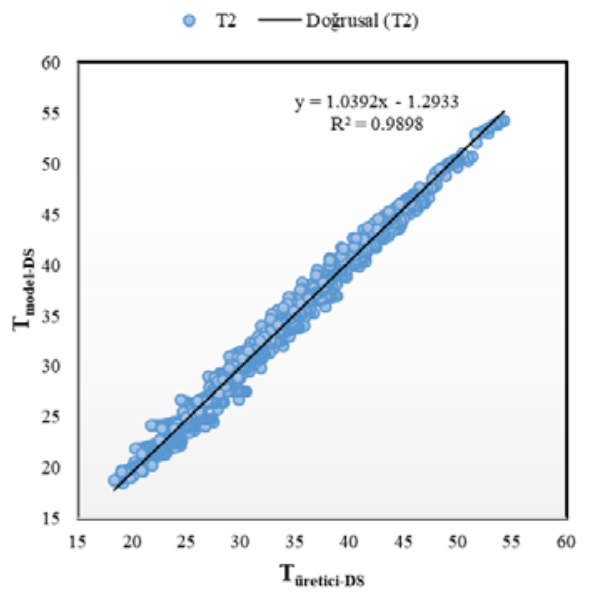

(a)

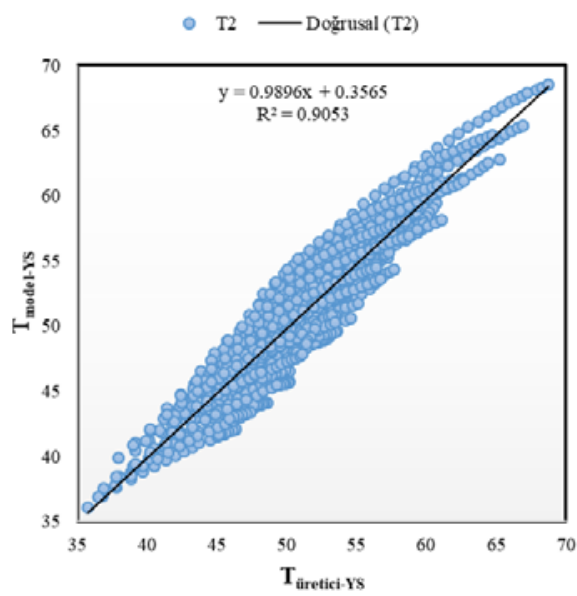

(c)

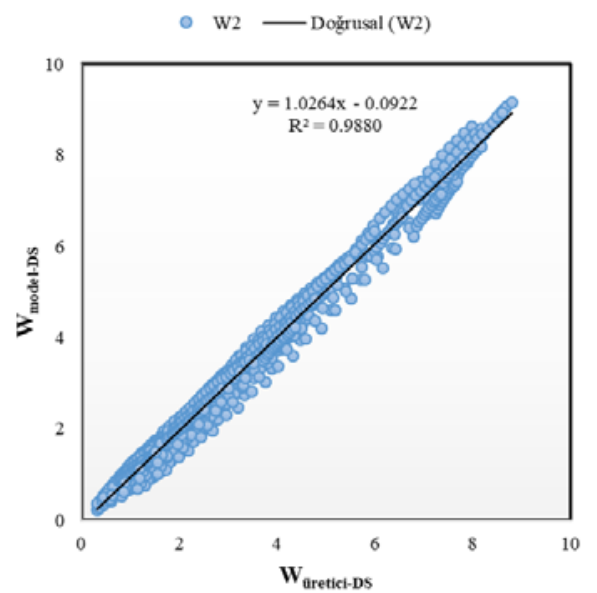

(b)

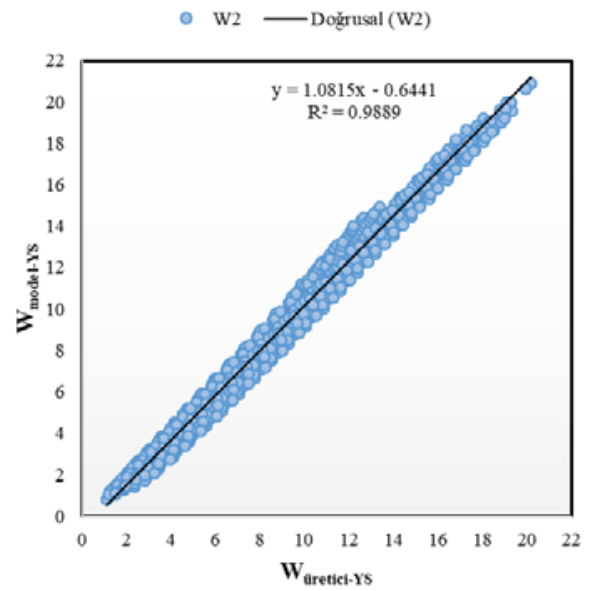

(d)

Şekil 7. Farklı debi ve giriş şartları için geliştirilen model ve üretici verilerinden elde edilen $T_{2}$ ve $W_{2}$ değerlerinin kıyaslanması

\section{SONUÇLAR}

Bu çalışmada, katı nem alıcı bir rotorun farklı debi ve rejenerasyon sicaklıklarında çalışma durumu için bir model geliştirilmiştir. Jurinak'ın modeli [8] baz alınarak geliştirilen model ile proses kanalından çıkan havanın sıcaklık ve mutlak nem değerleri hesaplanabilmektedir. Çalışma sonunda:

- Nem alıc rotora proses ve rejenerasyon havasından giren havanın şartlarına ve farklı debilere göre verimlilik faktörleri $\left(\eta_{1}\right.$ ve $\left.\eta_{2}\right)$ için eşitlikler üretilmiştir. Düşük ve yüksek sıcaklıklarda elde edilen verimlilik faktörlerinin doğruluk kriterleri olan RMSE ve MAE değerleri sirasıyla RMSE $\eta_{\text {F1-DS }}=0,004721$ ve MAE $\eta_{\text {F1-DS }}=0,008668, R M S E \eta_{\text {F2-DS }}=0,007660$ ve $\mathrm{MAE}_{\mathrm{F} 2-\mathrm{DS}}=0,025885, \mathrm{RMSE} \eta_{\mathrm{F} 1-\mathrm{YS}}=0,001447 \mathrm{ve}$ MAE $\eta_{F 1-Y S}=0,004611, R M S E \eta_{F 2-Y S}=0,071010$ ve MAE $\eta_{\mathrm{F} 2-\mathrm{YS}}=0,057195$ olarak elde edilmiştir.

- Oluşturulan verimlilik faktör eşitlikleri kullanılarak geliştirilen model ile proses kanalından çıkan havanın sıcaklık $\left(\mathrm{T}_{2}\right)$ ve mutlak nemi $\left(\mathrm{W}_{2}\right)$ sayısal olarak hesaplanmıştır. Elde edilen sonuçlar ile üretici verileri 
kıyaslandığında izlenen trendlerin birbirine uyumlu olduğu gözlemlenmiştir.

- Geliștirilen modelden elde edilen $T_{2}$ ve $W_{2}$ değerlerinin doğruluk kriterleri sirasıyla $\mathrm{RMSE}_{\mathrm{T}-\mathrm{DS}}=0,9246$ ve $\mathrm{MAE}_{\mathrm{T}-\mathrm{DS}}=0,7350$, $\mathrm{RMSE}_{\mathrm{W}-\mathrm{DS}}=0,2388$ ve $\mathrm{MAE}_{\mathrm{W}-\mathrm{DS}}=0,1828$, $\mathrm{RMSE}_{\mathrm{T}-\mathrm{YS}}=1,8934$ ve $\mathrm{MAE}_{\mathrm{T}-\mathrm{YS}}=1,5509$, $\mathrm{RMSE}_{\mathrm{W}-\mathrm{YS}}=0,6441$ ve $\mathrm{MAE}_{\mathrm{W}-\mathrm{YS}}=0,5220$ olarak elde edilmiştir.

- Sonuç olarak, yapılan bu çalışmayla geliştirilen modelin, farklı giriş havası şartlarında çalışan bir nem alıcı rotorun çıkış şartlarının belirlenebilmesi için kullanılabilirliğinin uygun olduğu görülmüştür.

\section{TEŞEKKÜR}

$\mathrm{Bu}$ çalışma Osmaniye Korkut Ata Üniversitesi Bilimsel Araştırma Projeleri Birimi (OKÜBAP) tarafindan OKÜBAP-2018-PT3-015 numaralı proje kapsamında desteklenmiştir. Desteklerinden dolayı OKÜBAP'a teşekkür ederiz.

\section{KAYNAKLAR}

1. Uçkan, I., Yilmaz, T., Hürdoğan, E., Büyükalaca, O., 2015. Development of an Artificial Neural Network Model for the Prediction of the Performance of a Silica-gel Desiccant Wheel, International Journal of Green Energy, 12, 1159-1168.

2. Cejudo, J.M., Moreno, R., Carrilo, A., 2002. Physical and Neural Network Models of a Silica-Gel Desiccant Wheel, Energy and Buildings, 34, 837-844.

3. İdiz, A., Koçak, Y.C., Akdemir, Ö., Güngör, A., 2017. İklimlendirme Sistemlerinde Evaporatif Soğutma Uygulamaları, 13. Ulusal Tesisat Mühendisliği Kongresi (TESKON), İzmir, Türkiye.

4. Parmar, H., Hindoliya, D.A., 2011. Artificial Neural Network Based Modelling of Desiccant Wheel, Energy and Buildings, 43, 3505-3513.

5. Qiu, G.Q., Riffat, S.B., 2010. Experimental Investigation of a Novel Air Dehumidifier Using Liquid Desiccant, International Journal of Green Energy, 7, 174-80.
6. Yutong, L., Hongxing, Y., 2010. Experimental Study of an Open-Cycle Solar Collector/Regenerator Using Liquid Desiccant for Air Conditioning, International Journal of Green Energy, 7, 273-88.

7. Li, H., Dai, Y.J., Li, Y., La, D., and Wang, R.Z. 2011. Experimental Investigation on a One-Rotor-Two-Stage Desiccant Cooling/Heating System Driven by Solar Air Collectors, Applied Thermal Engineering, 31, 3677-83.

8. Jurinak, J.J., 1982. Open-cycle Solid Desiccant Cooling-Component Models and System Simulation, Ph.D. Thesis, University of Wisconsin, Madison.

9. Howe, R., Rotary Desiccant Dehumidifier, 1983. TRNLIB-Libraries of User-Written TRNSYS Components, Solar Energy Laboratory, http://sel.me.wisc.edu/trnsys/trnlib/dessi.htm.

10. White, S.D., Goldsworthy, M., Reece, R., Spillmann, T., Gorur, A., Lee, D.Y., 2011. Characterization of Desiccant Wheels with Alternative Materials at Low Regeneration Temperatures, International Journal of refrigeration, 34, 1786-1791.

11. Stabat, P., Marchio, D., 2008. Heat-and-Mass Transfers Modelled for Rotary Desiccant Dehumidifiers, Applied Energy, 85, 128-142.

12. Panaras, G., Mathioulakis, E., Belessiotis, V., Kyriakis, N., 2010. Experimental Validation of a Simplified Approach for a Desiccant Wheel Model, Energy and Buildings, 42, 1719-1725.

13. Joudi, K.A., Dhaidan, N.S., 2001. Application of Solar Assisted Heating and Desiccant Cooling Systems for a Domestic Building, Energy Conversion and Management, 42, 995-1022.

14. Nia, F.E., Paassen, D.V., Saidi, M.H., 2006. Modeling and Simulation of Desiccant Wheel for Air Conditioning, Energy and Building, 38, 1230-9.

15. Beccali, M., Butera, F., Guanella, R., Adhikari, R.S., 2003. Simplified Models for the Performance Evaluation of Desiccant Wheel Dehumidification, International Journal of Energy Research, 27, 17-29. 
16. Sheridan, J.C., Mitchell, J.W., 1985. A Hydrid Solar Desiccant Cooling System, Solar Energy, 34(2), 187-193.

17. NovelAire 2012. Desiccant Wheel Simulation Program Version 2012. https://www.novelaire.com, (Erişim tarihi 10.02.19).

18. Hürdoğan, E., Büyükalaca, O., Yılmaz, T., Uçkan, İ., 2011. Nem Almalı Bir İklimlendirme Sisteminin Analizi, $6^{\text {th }}$ International Advanced Technologies Symposium (IATS'11), Elazı ̆̆, Türkiye.

19. Das, M., Akpinar, E.K., 2018. Investigation of Pear Drying Performance by Different Methods and Regression of Convective Heat Transfer Coefficient with Support Vector Machine, Applied Sciences, 1-16. 
